\title{
Participação no gerenciamento de bacia hidrográfica: o caso do Comitê Lago Guaíba*
}

\author{
Rafael Kruter Flores** \\ Maria Ceci Misoczky***
}

SuMÁRIo: 1. Introdução; 2. O tema da participação: uma breve revisão da teoria; 3. O caso do Comitê Lago Guaíba; 4. O caso da participação no Comitê Lago Guaíba à luz de referenciais teóricos; 5. Considerações finais.

Summary: 1 . Introduction; 2 . The topic of participation: a brief review of the theory; 3. The case of the Lake Guaíba Committee; 4. The case of participation in the Lake Guaíba Committee from a theoretical framework perspective; 5. Final remarks.

Palavras-chave: recursos hídricos; participação; sociedade civil.

KEY WORDs: water resources; participation; civil society.

Os modelos de gestão de recursos hídricos têm sofrido transformações em vários países, tornando-se cada vez mais complexos. O sistema adotado pela legislação brasileira é caracterizado por descentralização, planejamento por bacias, utilização de instrumentos normativos e econômicos, e participação da sociedade. Assumindo como situação problemática a participação de atores com interesses distintos no planejamento da bacia, este artigo analisa o processo participativo no Comitê Lago Guaíba como parte integrante do Sistema Estadual de Recursos Hídricos do Rio Grande do Sul. Como procedimento metodológico, analisaram-se as atas de reuniões do comitê na gestão 2001/02 e os conceitos, tipologias e fatores condicionantes do sucesso da participação sugeridos por diversos autores. A partir de índices de presença e contribuições na plenária identificaram-se membros omissos e atuantes e caracterizou-se a influência

\footnotetext{
* Artigo recebido em jul. 2006 e aceito em out. 2007.

** Mestre em administração/organizações pelo Programa de Pós Graduação em Administração da Universidade Federal do Rio Grande do Sul (PPGA/UFRGS), bacharel em administração/administração pública pela UFRGS. Endereço: Rua Fernandes Vieira, 533, ap. 203 - Bom Fim - CEP 90035-091, Porto Alegre, RS, Brasil. E-mail: rafakf@portoweb.com.br.

*** Docente e pesquisadora do PPGA/UFRGS. Doutora em administração pelo PPGA/UFRGS, mestre em planejamento urbano e regional. Endereço: Rua Washington Luiz, 855, sala 427 — Centro _ CEP 90010-460, Porto Alegre, RS, Brasil. E-mail: mcamisoczky@ea.ufrgs.br.
} 
da sociedade e a atuação do governo do estado. Uma efetiva participação de grupos e organizações da sociedade civil, bem como dos usuários da água nas decisões do comitê, foi um ponto positivo no caso estudado. Entretanto, o artigo revela que governo do estado não participa no processo do comitê.

Participating in river basin management: the case of the Lake Guaíba Committee Management models for water resources have been under transformation in many countries, becoming steadily more complex. The system adopted by the Brazilian law is characterized by decentralization, planning by basin, use of economic and regulatory instruments, and by social participation. This case study analyzes the participatory process of the Lake Guaíba Committee (Comitê Lago Guaíba), part of the Rio Grande do Sul State System of Water Resources (Sistema Estadual de Recursos Hídricos do Rio Grande do Sul). The study focuses on the roles of players with different interests in the basin planning. As methodological procedure, minutes from 2001/2002 Committee meetings, concepts, typologies, and factors associated with participation success, as suggested by many authors, were all analyzed. Based on attendance participation levels and during the meeting, the study indicated neglectful and active members, besides characterizing the influence of society and the role of the state government. The effective participation of civil society groups and organizations, as well as water consumers, in the committee's decisions was a positive point in the case study, although the state government did not participate in the committee's process.

\section{Introdução}

A importância estratégica da água e a sua escassez para atender às demandas humanas e dos ecossistemas têm levado vários países a promoverem uma reforma em seus sistemas de gestão de recursos hídricos. A evolução desses sistemas ocorreu, segundo Lanna (2000), em três fases que avançaram em níveis de complexidade e permitiram uma abordagem mais eficiente do problema. Tais mecanismos são os modelos burocrático, econômico-financeiro e o sistêmico de integração participativa. O último se caracteriza pela descentralização da gestão, planejamento estratégico em unidades de bacias hidrográficas e utilização de instrumentos normativos e econômicos. O modelo sistêmico tem sido aplicado em algumas unidades de bacia no Brasil.

Conforme determina o art. 26 da Constituição Federal, o lago Guaíba é um bem do estado do Rio Grande do Sul. A gestão de águas no estado está balizada pelo art. 171 da Constituição Estadual. Cánepa et al. (2001) identificam quatro princípios nesse dispositivo legal:

T\ gestão de águas com um Sistema Estadual de Recursos Hídricos (e não um órgão específico e centralizado); 
T— adoção de bacia hidrográfica como unidade básica de planejamento e intervenção;

т— estabelecimento da outorga e tarifação dos recursos hídricos (cobrança pela retirada e pelo despejo de efluentes);

T $\square$ reversão, para a respectiva bacia de arrecadação, da receita, devendo os recursos financeiros ser aplicados na própria gestão de águas da bacia.

Em 30 de dezembro de 1994 foi sancionada, no Rio Grande do Sul, a Lei no 10.350, que ficou conhecida como Lei das Águas. Esta serviu de modelo para a lei federal que viria a ser aprovada alguns anos depois, a Lei ㄲo 9.433/97.

Segundo Cánepa (2000) a Lei das Águas possui dois pontos importantes na gestão de recursos hídricos. O primeiro deles é o uso de instrumentos econômicos para a execução da política ambiental, pois assim pode-se trabalhar com padrões de qualidade estabelecidos pela sociedade e buscar alternativas com custos socialmente aceitáveis. O outro é a participação da comunidade, que deveria ocorrer em todas as etapas do processo de planejamento e intervenção na esfera dos recursos hídricos.

Este artigo analisa o processo participativo no Comitê Lago Guaíba, identificando os membros que participam, caracterizando a atuação da sociedade no planejamento e analisando as práticas adotadas a partir de referências teóricas sobre participação. Na próxima seção, é feita uma revisão da teoria sobre participação, suas definições e tipologias, além de sugestões de diversos autores para se obter sucesso em um processo participativo. Posteriormente é apresentado o comitê, suas atribuições e funcionamento. Finalmente, as observações e análises são comparadas com a teoria encontrada.

\section{O tema da participação: uma breve revisão da teoria}

Ainda que os mais diversos atores sociais, tanto na sociedade quanto no Estado, reivindiquem e apóiem a participação social, a democracia participativa, o controle social sobre o Estado, a realização de parcerias entre o Estado e a sociedade civil, trata-se apenas de uma "generalização do discurso da participação, na medida em que 'participação', democracia, controle social, parceria, não são conceitos com igual significado para os diversos atores e têm, para cada um deles, uma construção histórica diferente" (Carvalho, 1998:1).

O Banco Interamericano para o Desenvolvimento (BID, 2003) define participação no desenvolvimento como o processo pelo qual as pessoas e entidades exercem influência no controle das iniciativas de desenvolvimento e nas decisões sobre recursos que as afetam. 
Alguns utilizam somente participação, outros citam participação cidadã, societária, ou participação no desenvolvimento. Para Modesto (1999), participar significa intervir num processo decisório qualquer e, no âmbito da administração pública, corresponde a todas as formas de interferência de terceiros na realização da função administrativa do Estado. Teixeira (2007) define a participação cidadã como um processo complexo e contraditório entre sociedade civil, Estado e mercado, em que os papéis se redefinem pelo fortalecimento dessa sociedade civil mediante a atuação organizada dos indivíduos, grupos e associações.

Segundo Gohn (2001), participação é uma das palavras mais utilizadas no vocabulário político, científico e popular da modernidade. A autora conceitua o tema segundo quatro interpretações. Na interpretação liberal, a participação objetiva o fortalecimento da sociedade civil, a desestimulação da intervenção governamental e a ampliação de canais de informação aos cidadãos, de forma que eles possam manifestar suas preferências antes que as decisões sejam tomadas (pode ser corporativa ou comunitária). Em outra interpretação, a autoritária, a participação é orientada para a integração e o controle social da sociedade e da política, podendo ocorrer em regimes políticos autoritários ou em regimes democráticos. A integração se dá através de políticas públicas que estimulam, de cima para baixo, a promoção de programas para diluir conflitos sociais. A terceira interpretação é a democrática, na qual a participação é um fenômeno que se desenvolve tanto na sociedade civil quanto nas instituições, em forma de políticas. Na interpretação revolucionária, a participação estrutura-se em coletivos organizados para lutar contra as relações de dominação e pela divisão do poder político.

Pedro Demo (1993) tem sido um dos autores brasileiros mais preocupados com o tema da participação na perspectiva da emancipação, considerada um antídoto contra a tendência histórica de dominação e exclusão social que caracteriza nossa sociedade. Para Demo (1996) a participação é conquistada, no processo histórico, juntamente com as condições de autodeterminação, que não podem ser dadas, outorgadas ou impostas. Uma participação atribuída representa, para esse autor, um conceito paternalista que, no fundo, representa uma antiparticipação. Para Demo (1996:94-97) a participação somente é revelada por meio de canais que a sociedade disponibiliza. Entre eles destacamos:

т $\square$ organização da sociedade civil — forma mais operacional que exige a competência de grupos com a representatividade de lideranças, legitimidade dos processos, participação da base e planejamento participativo auto-sustentado, em que "o objetivo histórico é atingir uma trama bem urdida e sólida de organizações de caráter popular que permita plantar a democracia como algo cotidiano"; 
т $\square$ planejamento participativo - um canal baseado no regime da autogestão e co-gestão na conjunção entre população e governos, não valendo a banalização de distribuir participação por atacado, mas fundamentalmente a capacidade de "formular uma situação de negociação mútua".

De acordo com Teixeira (2007), a participação pode ser percebida a partir de quatro dimensões.

Participação no processo de tomada de decisão. Diz respeito a quem toma as decisões no Estado e como isso acontece, ao sujeito e ao processo decisório. Quanto ao sujeito, define quem são os atores: elites tecnicamente preparadas e selecionadas via processo eleitoral; ou cidadãos, de forma direta ou por mecanismo que permita sua expressão e deliberação. Quanto ao processo, verifica se a seleção implica apenas a escolha dos decisores, delegando a esses total liberdade de ação, ou se é mais objetiva envolvendo critérios e elementos de decisão.

Dimensão educativa e integrativa do processo de participação. A capacitação para a participação política é gerada pela própria prática ou experiências pessoais rotineiras em que se adquire habilidades e procedimentos democráticos. Trata-se do tipo de participação dos movimentos sociais, ONGs e grupos de cidadãos, capaz de sedimentar um sentimento maior de identidade e de integração.

Participação como controle público. A participação é um instrumento de controle do Estado pela sociedade. Esse entendimento de controle público tem dois aspectos básicos: o primeiro corresponde à accountability, ou seja, a prestação de contas conforme parâmetros estabelecidos socialmente em espaços públicos próprios; o segundo, decorrente do primeiro, consiste na responsabilização dos agentes políticos pelos atos praticados em nome da sociedade, conforme os procedimentos estabelecidos nas leis e padrões éticos vigentes. $\mathrm{O}$ exercício desse controle requer a organização, estruturação e capacitação da sociedade civil em múltiplos espaços públicos, antes e durante a implementação das políticas, tendo como parâmetros variáveis técnicas, exigências de eqüidade social e aspectos normativos.

Dimensão expressivo-simbólica da participação. Essa dimensão aborda formas de participação que não se voltam para o institucional, embora suas ações possam ter desdobramentos e impactos nesse âmbito. Os mecanismos de participação utilizados para esse fim são específicos e diversificados, muitos resultantes da criatividade e da não-submissão aos padrões estabelecidos, indo de forma leves e lúdicas, como o abraço de milhares de pessoas em um local que se quer preservar, às mais agressivas, como o fechamento de uma rua, uma greve de fome, protestos etc. (Teixeira, 2007). 
Arnstein (1998) construiu o que chamou de escada da participação cidadã (quadro), uma escada em que a participação dos cidadãos aumenta à medida que se sobe. Segundo a autora, nos dois primeiros degraus (manipulação e terapia) não existe participação. Os três seguintes (informação, consulta e pacificação) sugerem níveis em que acontece uma "política do menor esforço". A partir do sexto degrau, parceria, o cidadão começa a ter poder.

\section{Escada da participação cidadã}

\begin{tabular}{|c|c|}
\hline 8. Controle pelo cidadão & $\begin{array}{l}\text { Cidadãos responsáveis pelo planejamento, pela política, assumindo a } \\
\text { gestão em sua totalidade, sem intermediários. }\end{array}$ \\
\hline 7. Delegação de poder & $\begin{array}{l}\text { Cidadãos ocupando a maioria dos assentos nos comitês, com poder } \\
\text { delegado para tomar decisões. Nesse caso o público tem poder para } \\
\text { assegurar as contas do programa para si. }\end{array}$ \\
\hline 6. Parceria & $\begin{array}{l}\text { Poder distribuído por uma negociação entre cidadãos e detentores do } \\
\text { poder. O planejamento e as decisões são divididos pelos comitês. }\end{array}$ \\
\hline 5. Pacificação & $\begin{array}{l}\text { O cidadão começa a ter um certo grau de influência nas decisões, } \\
\text { podendo participar dos processos de tomada de decisão, entretanto, } \\
\text { não existe a obrigação dos tomadores de decisão de levar em conta o } \\
\text { que ouviram. }\end{array}$ \\
\hline 4. Consulta & $\begin{array}{l}\text { Caracterizado por pesquisas de participação, reuniões de vizinhança } \\
\text { etc. Segundo os autores, serve somente como fachada, não possui } \\
\text { muita implicação prática. }\end{array}$ \\
\hline 3. Informação & $\begin{array}{l}\text { Informar as pessoas sobre seus direitos, responsabilidades e opções. } \\
\text { Entretanto, trata-se de um fluxo de informação somente de cima para } \\
\text { baixo. }\end{array}$ \\
\hline 2. Terapia & $\begin{array}{l}\text { Os técnicos de órgãos públicos se escondem atrás de conselhos e } \\
\text { comitês participativos para não assumir erros cometidos por eles e } \\
\text { diluir a responsabilidade. }\end{array}$ \\
\hline 1. Manipulação & $\begin{array}{l}\text { Tem como objetivo permitir que os atores sociais que conduzem } \\
\text { o processo possam educar as pessoas. Manifesta-se em conselhos } \\
\text { onde os conselheiros não dispõem de informações, conhecimento e } \\
\text { assessoria técnica independente necessários para tomar decisões por } \\
\text { conta própria. }\end{array}$ \\
\hline
\end{tabular}

Fonte: Arnstein (1998). 
Antes de prosseguir é necessário distinguir entre participação e representação. Representar significa ser a imagem ou a reprodução de algo (Ferreira, 1975). O foco deste artigo é participação, não representação.

\section{Algumas condições para o sucesso do processo participativo}

Segundo o BID (2003), para que o processo participativo atinja seus objetivos, em primeiro lugar, deve deliberar sobre os rumos de um bem comum e oferecer benefícios reais à sociedade e aos indivíduos. Deve ser feita a estruturação de uma demanda e, posteriormente, a geração de soluções. Os possíveis e prováveis conflitos entre as partes interessadas devem se referir mais aos meios do que aos objetivos finais da política, porque nesse caso a dificuldade em encontrar soluções aumenta, podendo tornar-se inviável. O documento também ressalta a importância do comprometimento do órgão promotor com o processo.

Rafaghelli (2001) sugere a criação de espaços e reuniões regulares onde se produza informação clara e transparente (regras, planejamento e resultados), a fim de obter maior interação e comunicação para que as decisões sejam tomadas com a opinião de todos;

Segundo Goma (2002) deve-se despender menos tempo e esforço participativo na elaboração de diagnósticos exaustivos e estratégias genéricas para envolvê-los em um documento aprovado com solenidades, e dedicar esse tempo à articulação de redes participativas, entendendo que elas são partes intrínsecas dos processos do governo, e sua existência é condicionante para a aprovação de planos.

Para Costa (2001) a participação societária deve ser baseada numa institucionalidade que não se reduz a formalidades, mas a regras e procedimentos que traduzem determinados conteúdos. Conforme o autor, a expectativa em torno dessa nova institucionalidade é que se revele capaz de fazer do Estado um autêntico espaço público, no qual prevaleça a vontade direta dos cidadãos e um controle social efetivo das ações estatais.

\section{Dificuldades para a implementação da participação}

Lima (2001:14) lista algumas dificuldades encontradas em instâncias participativas (conselhos de meio ambiente e audiência pública de estudos de impacto ambiental).

As discussões intermináveis, a falta de quórum das plenárias, as pautas extensas, as atas que não são lavradas, a paridade ou a falta dela na composição dos 
conselhos, a fragilidade da representação institucional, a descontinuidade e descompromissos dos representantes, a falta de apoio ou condições de participação para pessoas ou organizações realmente interessadas, os diferentes níveis de informação e qualificação, o gigantismo da estrutura de uns em contraste com a fragilidade e desorganização de outros, a manipulação da participação e a cooptação dos representantes são apenas algumas das dificuldades...

\section{Vantagens e desvantagens}

A bibliografia consultada apontou as principais vantagens e desvantagens encontradas em processos participativos.

As vantagens encontradas são:

T $\square$ reduz os custos de obtenção de dados ambientais, sociais e culturais, bem como sobre as necessidades dos atores (BID, 2003);

$\mathrm{T} \square$ fortalece as instituições locais em suas capacidades administrativas (BID, 2003);

T[ aumenta a credibilidade da avaliação (as pessoas confiam nas informações providas por elas mesmas) (BID, 2003);

т $\square$ concilia diferentes visões, pois possui defensores em diferentes correntes ideológicas como liberais, marxistas e anarquistas (todos têm restrições em relação ao Estado) (Costa, 2001).

Algumas desvantagens:

T\ não substitui um projeto nos assuntos técnicos ou de financiamento (BID, 2003);

T— aumenta os custos associados à identificação de pessoas interessadas (BID, 2003);

T $\square$ perde legitimidade com a falta de reconhecimento e aceitação (BID, 2003);

T $\square$ perde com o limite da disposição dos cidadãos (se muito exigida, poderá pôr em risco a representatividade) (Font, 2001);

T $\square$ pode permitir alguns atores de apoderarem-se de mais do que dividem (Estrella e Gaventa, 1997);

T\ gera conflitos socioculturais (Estrella e Gaventa, 1997);

T $\square$ pode causar alienação por parte do governo (Estrella e Gaventa, 1997). 


\section{As principais formas de participação}

Carvalho (1998) ressalta que existe uma tendência no país de entender como práticas participativas aquelas nas quais há uma co-gestão entre Estado e sociedade, e afirma que existem hoje no Brasil três formas de participação.

Conselhos gestores - espaços de negociação e co-gestão acessível aos participantes dos movimentos sociais. São instâncias de formação de políticas que gozam de um alto conceito de respeitabilidade como espaços transparentes e comprometidos com o interesse público.

Orçamentos participativos - instrumentos com grande potencial de democratização do poder e de inversão de prioridades, garantindo que a agenda e os recursos públicos se voltem realmente para os interesses públicos. Propiciam a interlocução entre atores com grande diversidade de interesses, desafiando o ato de pautar-se somente por argumentos que fundamentam racionalmente tais interesses.

Parcerias - cooperativismo, mutirões e outras atividades autogestionárias que favorecem o processo de construção de identidade e aprendizado de gestão da vida coletiva, que se inicia com a convivência e a tomada de decisões cotidianas, desde as questões mais simples até os processos complexos de construção e administração das obras, de gestão dos recursos públicos e as atividades de operacionalização desses programas.

\section{0 caso do Comitê Lago Guaíba}

O lago Guaíba é formado pelas águas dos rios Gravataí, Sinos, Caí e Jacuí que desembocam no delta do Jacuí. Banha os municípios de Porto Alegre, Eldorado do Sul, Guaíba, Barra do Ribeiro e Viamão. Os principais impactos ambientas no lago devem-se aos lançamentos do esgoto de Porto Alegre e das águas poluídas dos rios Gravataí e Sinos. As principais indústrias da região são a metalúrgica, de celulose e de produtos alimentares (Pró-Guaíba, 2003).

Em 29 de outubro de 1998, o Decreto no 38.989 do governo do estado do Rio Grande do Sul determinou a criação do Comitê de Gerenciamento da Bacia Hidrográfica do Lago Guaíba, e definiu sua composição, conforme a proporção prevista na lei: 16 representantes dos usuários da água, 16 representantes da população da bacia e oito representantes do governo. Este decreto especifica a estrutura dos grupos por categorias. As categorias do grupo dos representantes de usuários da água são abastecimento público, esgotamento sanitário, drenagem urbana, indústria, agropecuária, efluentes líquidos, provenientes de resíduos sólidos, turismo, esporte e lazer, pesca artesanal, comercial e aqüicul- 
tura e navegação. As categorias do grupo dos representantes da população da bacia são os legislativos municipais, organizações ambientalistas, organizações comunitárias e clubes de serviço, instituições de ensino superior e pesquisa, associações técnicas, científicas e classistas e organizações sindicais (Rio Grande do Sul, 1994).

O grupo dos representantes dos órgãos da administração direta federal e estadual não se subdivide.

Em sua primeira gestão o Comitê Lago Guaíba buscou consolidar-se e firmar-se como um grupo coeso. Foram estruturados três grupos de trabalho que funcionaram durante dois anos - um para estudos e montagem de uma proposta de construção do enquadramento (definição dos usos que se deseja fazer da água), outro de comunicação social e educação ambiental e outro de relações institucionais.

No período da segunda gestão a principal atividade desenvolvida pelo comitê foi a estruturação de proposta de enquadramento, articulada com os estudos preliminares para a construção do Plano de Bacia (Cánepa et al., 2003): diretrizes, ações e prazos que visa garantir que a quantidade e a qualidade da água sejam compatíveis com os objetivos propostos no Enquadramento (Comitê Lago Guaíba, 2002n).

Além dos membros do comitê, existem quatro órgãos de licenciamento e fiscalização que participam das reuniões mas não possuem direito a voto nas plenárias: Fundação Estadual de Proteção Ambiental (Fepam), Departamento de Recursos Hídricos (DRH), Secretaria Municipal do Meio Ambiente de Porto Alegre (SMAM), Fundação Metropolitana de Planejamento (Metroplan).

As atribuições dos comitês de bacia estão especificadas no art. 19 da Lei no 10.350/94:

I - encaminhar ao Departamento de Recursos Hídricos a proposta relativa à bacia contemplando, inclusive, objetivos de qualidade para ser incluída no anteprojeto de lei do Plano Estadual de Recursos Hídricos;

II - conhecer e manifestar-se sobre o anteprojeto de lei do Plano Estadual de Recursos Hídricos previamente ao seu encaminhamento ao governador do estado;

III — aprovar o plano da respectiva bacia hidrográfica e acompanhar sua implementação;

IV — apreciar o relatório anual sobre a situação dos recursos hídricos no Rio Grande do Sul;

$\mathrm{V}$ - propor ao órgão competente o enquadramento dos corpos de água da bacia hidrográfica em classes de uso e conservação;

VI - aprovar os valores a serem cobrados pelo uso da água da bacia hidrográfica; 
VII — realizar o rateio dos custos de obras de interesse comum a serem executados na bacia hidrográfica;

VIII - aprovar os programas anuais e plurianuais de investimentos em serviços e obras de interesse comum a serem executados na bacia hidrográfica tendo por base o plano da respectiva bacia hidrográfica;

IX - compatibilizar os interesses dos diferentes usuários da água, dirimindo, em primeira instância, os eventuais conflitos.

Rio Grande do Sul (1994)

O Comitê Lago Guaíba tem suas atividades balizadas por um Regimento Interno, que determina a existência de uma diretoria composta por presidente e vice-presidente, uma Comissão Permanente de Assessoramento composta pelo secretário executivo e por representantes das entidades-membros. São realizadas reuniões ordinárias a cada dois meses e extraordinárias sempre que necessário. As entidades-membros são eleitas a cada dois anos, já as entidades da administração direta, federal e estadual são indicadas a cada dois anos pelos respectivos poderes executivos (Comitê Lago Guaíba, 1999).

Em seu estágio inicial, um comitê tem como principal atribuição aprovar um Plano de Bacia. Somente na gestão 2001/02 a elaboração do Plano de Bacia do Comitê Lago Guaíba apresentou resultados (iniciais) concretos, por isso este artigo considera o processo do comitê somente nesse período.

\section{Procedimentos metodológicos}

A primeira parte do relato que segue é uma análise das presenças e intervenções de cada integrante por reunião. Foram consideradas 20 reuniões da gestão 2001/02, incluindo ordinárias e extraordinárias. Foram, então, relacionados o índice de presença e o número de reuniões em que cada integrante fez alguma intervenção sobre o assunto em pauta. Os suplentes que tiveram mais de $50 \%$ de presença também foram considerados na análise. Esse procedimento visou identificar as instituições que presenciam as reuniões e, delas, as que participam (considerando o conceito de Modesto, 1999).

A segunda parte é a descrição das deliberações relativas à elaboração do Plano de Bacia. Após identificadas as principais decisões, foram investigados os seus responsáveis, ou pelo menos aqueles que contribuíram de forma decisiva nas mesmas. Posteriormente, foi feita uma comparação das influências e contribuições de entidades que representam a sociedade civil com a influência das entidades usuárias e do governo para caracterizar a participação no comitê conforme a escada da participação cidadã de Arnstein (1998). 
A terceira e última parte do estudo foi feita a partir de observações não-participantes. Tais observações tiveram o intuito de compreender o funcionamento do comitê e compará-lo com ações que a literatura aponta como determinantes de sucesso ou insucesso em um processo participativo.

\section{O processo participativo no Comitê Lago Guaíba}

Os dados obtidos na análise das 20 reuniões realizadas durante a gestão 2001/02 estão resumidos na tabela.

\section{Presenças e intervenções*}

\begin{tabular}{|c|c|c|c|c|c|}
\hline Usuários da água & Entidade & $\begin{array}{c}\text { Total de } \\
\text { presenças }\end{array}$ & $\begin{array}{c}\text { Total de } \\
\text { intervenções }\end{array}$ & $\begin{array}{c}\text { Presenças } \\
(\%)\end{array}$ & $\begin{array}{c}\text { Intervenções } \\
(\%)\end{array}$ \\
\hline \multirow{4}{*}{$\begin{array}{l}\text { Abastecimento } \\
\text { público }\end{array}$} & Corsan & 15 & 6 & 68 & 40 \\
\hline & Corsan & 19 & 16 & 95 & 84 \\
\hline & DMAE & 7 & 1 & 35 & 14 \\
\hline & DMAE & 17 & 2 & 85 & 12 \\
\hline \multirow{3}{*}{$\begin{array}{l}\text { Esgotamento } \\
\text { sanitário }\end{array}$} & Corsan & 8 & 0 & 40 & 0 \\
\hline & DMAE & 12 & 3 & 60 & 25 \\
\hline & DMAE (suplente) & 10 & 1 & 50 & 10 \\
\hline \multirow{3}{*}{$\begin{array}{l}\text { Drenagem } \\
\text { urbana }\end{array}$} & DEP/PMPA & 13 & 4 & 65 & 31 \\
\hline & Prefeitura de & & & 90 & 44 \\
\hline & Guaíba & 18 & 8 & & \\
\hline \multirow[t]{3}{*}{ Indústria } & Fiergs & 12 & 5 & 60 & 42 \\
\hline & Sindareia & 14 & 3 & 70 & 21 \\
\hline & Acigua (suplente) & 16 & 4 & 80 & 25 \\
\hline \multirow[t]{3}{*}{ Agropecuária } & Ageflor & 13 & 10 & 65 & 77 \\
\hline & $\begin{array}{l}\text { Sind. Rural Guaíba } \\
\text { Sind. Rural B. do }\end{array}$ & 9 & 0 & 45 & 0 \\
\hline & Ribeiro & 11 & 7 & 55 & 64 \\
\hline $\begin{array}{l}\text { Efluentes } \\
\text { líquidos }\end{array}$ & DMLU & 17 & 7 & 85 & 41 \\
\hline $\begin{array}{l}\text { Turismo, esporte } \\
\text { e lazer }\end{array}$ & Fevers & 11 & 8 & 55 & 73 \\
\hline Pesca & Z5 & 4 & 2 & 20 & 50 \\
\hline Navegação & Sindarsul & 16 & 5 & 80 & 31 \\
\hline
\end{tabular}




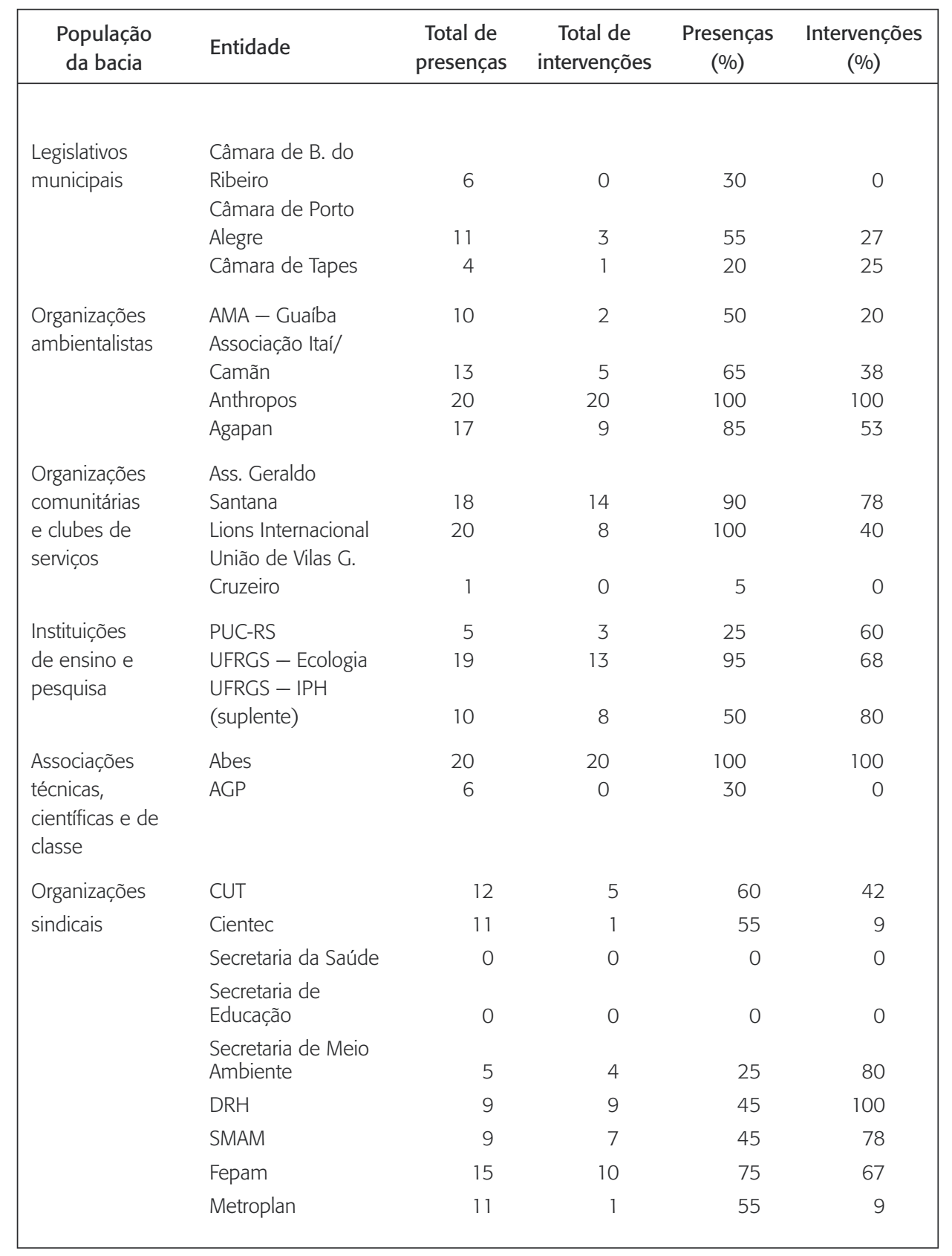

* O percentual de presença foi calculado dividindo-se o número de presenças pelo número de reuniões analisadas. O percentual de intervenções foi calculado dividindo-se o número de intervenções feitas nas 20 reuniões pelo número de presenças. 
Considerando os usuários da água, com exceção dos representantes da pesca, Z5, e da agropecuária, Sindicato Rural de Guaíba, pode-se concluir que as instituições participaram das reuniões. Nenhuma vaga ficou em aberto, e alguns suplentes presenciaram mais da metade das reuniões. Destaque para o DMAE e a Corsan, que participam do comitê com mais de um representante.

A população da bacia apresentou o primeiro problema de vaga não preenchida nas deliberações do comitê. A categoria dos legislativos municipais, que não participou das deliberações da gestão 2001/02, teve uma vaga em aberto. Ao contrário, os outros casos de não-participação - União de Vilas da Grande Cruzeiro, AGP e PUC-RS - estão cada um em uma categoria, o que dilui a baixa representação, pois as outras entidades de suas categorias participaram. Destaque para Anthropos e Abes-RS, cujos representantes são diretamente responsáveis pelo funcionamento do comitê.

A representação do governo na gestão 2001/02 do comitê foi quase nula. Responsável por oito votos nas plenárias, somente duas entidades presenciaram algumas poucas reuniões. Os órgãos de fiscalização tiveram presença regular e, com exceção da Metroplan, fizeram várias intervenções nas pautas.

Esta análise revela a diferença existente entre os interesses das três partes envolvidas na gestão da bacia do Guaíba. Pode-se considerar que as organizações mais interessadas (que mais participaram) são aquelas que utilizam a água em suas atividades comerciais, seja na distribuição, em processos produtivos, ou como meio de transporte e lazer.

Em segundo lugar, aparecem as organizações que têm interesse na bacia por ela ser parte do seu meio. São representantes daqueles que utilizam a água no dia-a-dia, e que pagam pelos serviços das organizações usuárias da água, seja para alimentação, higiene, lazer etc. É onde o poder local mencionado por Gohn (2003) exerce influência.

As entidades que representam o governo do estado, e correspondem a $20 \%$ do comitê, não participaram das deliberações. Aqui aparece uma das dificuldades de se implementar a participação citada por Lima (2001), que é a descontinuidade e o descaso de alguns representantes. Por serem representantes de um mesmo grupo, o das entidades da administração direta, confirma-se também uma das desvantagens dos processos participativos citadas pelo BID (2003), que é a alienação por parte do governo.

O comitê é responsável pela elaboração de um plano que deve passar pela instância de órgãos fiscalizadores do governo, ou seja, tem sua a ação restrita pela lei. Essa premissa sugere que o descaso dos representantes do governo no comitê se dá justamente pelo fato de que as definições das plenárias não são definitivas, e retornam ao crivo do governo mesmo que em instâncias diferentes. 


\section{A sociedade e o comitê}

As atividades do comitê no período estudado seguiram as diretrizes do Planejamento de Gestão aprovado logo no início de 2001. O planejamento tinha como principal diretriz a elaboração de uma proposta de enquadramento dos cursos d'água da bacia para ser encaminhada à Fepam (conforme as atribuições do comitê). As outras diretrizes eram a consolidação do comitê e a consolidação da gestão de recursos hídricos.

Para a realização das atividades propostas foram mantidos os grupos de trabalho (GTs) e a Comissão Permanente de Assessoramento (CPA). Os grupos de trabalho são compostos por espontânea vontade dos membros do comitê para a realização dos trabalhos internos. A CPA está prevista no Regimento Interno e, além de assessorar o presidente, tem a função de encaminhar à diretoria e submeter à aprovação do plenário qualquer ação de interesse da bacia (Comitê Lago Guaíba, 1999).

Atuaram diretamente na elaboração da proposta de enquadramento o GT Enquadramento e a CPA. A seguir, a descrição das ações.

Identificação e disseminação de informações sobre o processo de enquadramento de recursos hídricos e sobre a bacia hidrográfica do Guaíba, dentro e fora do comitê. Foi contratada uma empresa consultora para realizar estudos técnicos com o objetivo de gerar informações necessárias ao processo, e promovido um workshop para definição do método a ser adotado na construção da proposta de enquadramento.

Articulação da sociedade da bacia para a estruturação da proposta de enquadramento, ou seja, ampliar a consulta para além dos representantes do comitê. O GT Enquadramento estruturou uma estratégia de mobilização da sociedade por meio de quatro etapas: encontro preparatório, reuniões temáticas para debate do diagnóstico, primeira e segunda consulta pública.

A CPA se reuniu 31 vezes durante a gestão e teve papel fundamental nas questões internas do comitê. No início da gestão muitos membros se candidataram a trabalhar pela comissão, entretanto, uma análise das listas de presença de 29 reuniões da CPA revelou que somente alguns estiveram presentes em mais da metade delas: Abes-RS, Corsan (dois representantes), Lions, DMAE, Fiergs, Anthropos e UFRGS. Assim, a composição da CPA foi, de certa forma, equilibrada considerando a representação dos membros quanto aos grupos. Três organizações usuárias da água, sendo que a Corsan teve seus dois representantes titulares atuando; e quatro organizações da população da bacia, duas delas representadas pela diretoria do comitê.

A composição do GT Enquadramento chegou a ter mais de 20 membros inscritos. Foram analisadas 13 listas de presença das reuniões do grupo durante 
o período e, de todos os membros inscritos, somente sete tiveram mais de 50\% de presença nos encontros. Tais membros foram os representantes das seguintes organizações: Corsan, Fepam, Anthropos, SMAM, Abes, Fiergs e DMAE. Nessa composição predominam organizações usuárias da água (três representantes). Aparecem também duas organizações que fazem parte do grupo de fiscalização (não têm direito a voto) e duas organizações da população da bacia.

Utilizando as definições do BID (2003) verificamos uma influência de dois representantes da sociedade civil, que se traduz em 28\% do GT Enquadramento (considerando os membros efetivos). Cabe aqui a ressalva de que essa representação está dada pelo presidente e pelo secretário executivo, que são os principais responsáveis pelo funcionamento do comitê.

Pela análise das atas de reuniões, na gestão estudada, ficou claro que as articulações foram feitas com uma dinâmica de consultas ao plenário e estruturação de propostas. As decisões tomadas pelo comitê, que definiram os rumos do processo, foram todas propostas pelo GT Enquadramento, tendo como base sugestões do plenário. A seguir estão sintetizadas quatro decisões consideradas principais, bem como as intervenções feitas anteriormente a elas.

Decisão: contratação de uma empresa responsável pela realização de estudos técnicos. O representante da UFRGS colocou a importância da relação do processo de enquadramento com estudos técnicos a serem desenvolvidos e comunicou a existência de fundos setoriais no Fundo de Recursos Hídricos que poderiam ser um atrativo de financiamento para esses estudos. O secretário executivo destacou a importância de se ter maior conhecimento sobre os usos da água e do solo na bacia para fundamentar o processo de enquadramento.

Decisão: realização de um workshop para a estruturação de um processo de discussão dos estudos técnicos com a população. A representante do Lions Clube salientou a necessidade de que sejam feitos seminários para esclarecer e ouvir a população.

Decisão: estruturação de um folder explicativo do processo. Um dos grupos definidos no workshop ressaltou a necessidade da disponibilização de informações básicas em linguagem adequada em um material informativo. $\mathrm{O}$ mesmo grupo sugeriu maior detalhamento de alguns pontos do termo de referência apresentado.

A definição do processo em quatro etapas pode ser considerada uma das decisões principais, entretanto ela surgiu a partir das definições anteriores.

Percebe-se que, das cinco sugestões, três foram feitas por representantes da sociedade, e as outras duas surgiram de uma atividade realizada em grupo (que aconteceu no evento proposto a partir de uma sugestão de uma representante da sociedade). Aqui aparece uma maior influência dos representantes da sociedade civil no comitê, por meio de contribuições para a concretização das atividades. 


\section{O caso da participação no Comitê Lago Guaíba à luz de referenciais teóricos}

Antes de estabelecer uma relação do processo participativo do comitê com a tipologia de Arnstein (1998), cabe analisá-lo a partir da dimensão tomada de decisão, citada por Teixeira (2007). O autor coloca dois fatores a serem considerados: o sujeito (os atores que tomam as decisões) e o processo decisório (como isso acontece). Analisando o processo do comitê foram identificadas três fases: articulação, participação e tomada de decisão.

A fase da articulação está centralizada na diretoria (para facilitar a análise, foram considerados como componentes da diretoria o presidente, a vice-presidente e o secretário executivo), na Comissão Permanente de Assessoramento e nos grupos de trabalho. A diretoria é composta por três membros, sendo dois deles representantes da sociedade civil, o presidente e o secretário executivo. A análise das atas mostrou que os dois juntos são responsáveis pela dinâmica do comitê.

A CPA, na gestão 2001/02, teve oito membros atuando com afinco, dos quais quatro representavam a sociedade (Abes, Anthropos, Lions e UFRGS).

Responsável por uma ação mais específica, porém vital para a gestão dos recursos hídricos proposta pela lei, o GT Enquadramento foi encarregado de articular o início do Plano de Bacia. Teve maior representação dos usuários da água, pois a sociedade atuou somente nas figuras do presidente e do secretário executivo.

Dos três grupos responsáveis pela articulação do comitê um apresentou maior influência da sociedade (diretoria), outro apresentou equilíbrio (CPA), e o outro foi mais influenciado pelos usuários (GT Enquadramento). De forma geral, se verificou um equilíbrio na influência das organizações usuárias e da sociedade nas articulações do comitê na gestão 2001/02.

A fase da participação se refere ao conceito de Modesto (1999), ou seja, intervenção nas reuniões. O processo de enquadramento analisado apontou a intervenção de atores da sociedade que foram vitais para subsidiar a elaboração de sugestões pelo GT Enquadramento, e posterior aprovação do plenário. Na fase da participação verificou-se uma efetiva ação da sociedade civil nas decisões do comitê.

A terceira e última fase, tomada de decisão, se refere ao fator sujeito de Teixeira (2007). Todas as decisões do comitê são colocadas em plenária. Para identificar a participação da sociedade nessa fase bastaria realizar um simples cálculo de proporção. Entretanto, a primeira parte do trabalho revelou que a composição do comitê na teoria é diferente da prática, pois muitos representantes não participam das reuniões e conseqüentemente não participam das 
tomadas de decisão. $\mathbf{O}$ equilíbrio entre sociedade e usuário encontrado na articulação também aconteceu na fase de tomada de decisão.

Para caracterizar esse processo complexo de acordo com a escada de Arnstein (1998), foi considerado o conceito de cidadão proposto por Lima (2001). O equilíbrio encontrado na primeira parte do trabalho e nas fases de articulação e tomada de decisão, aliado à omissão dos representantes do governo, sugere que o comitê se encontra no sexto degrau da escada, "parcerias". Há, entretanto, que ser feita uma adaptação, pois os cidadãos não realizam a parceria com os detentores do poder como sugere a autora, e sim com organizações usuárias da água, negociando com elas uma forma de planejamento das águas da bacia.

Os degraus da escada de Arnstein (1998) quantificam a participação desde uma situação em que não existe, até uma situação onde ela está no topo das decisões. Em cada um dos níveis onde existe de fato a participação, muitos outros fatores podem levar um processo participativo ao sucesso ou não. A literatura apontou alguns deles.

Inicialmente são analisados os requisitos apresentados pelo BID (2003), dos quais o processo participativo do comitê preenche alguns, como o primeiro - a deliberação sobre os rumos de um bem comum, a água. Entretanto, ainda não se pode afirmar que o comitê oferece benefícios reais à sociedade e aos indivíduos, pois o Plano de Bacia ainda está sendo definido e tais benefícios somente poderão ser oferecidos com a sua implantação.

A segunda parte do trabalho mostrou a evolução de uma estruturação de demanda e geração de soluções, conforme sugere o BID. As demandas foram os estudos técnicos necessários para subsidiar o processo de enquadramento, solucionadas pela contratação de uma empresa terceirizada; e a necessidade de articulação dos estudos com a opinião da sociedade, solucionada por meio de eventos de consulta.

Foram considerados os objetivos finais da política do comitê como a elaboração do Plano de Bacia e a definição dos instrumentos de gestão nele contidos (cobrança e investimentos). Os meios são as diretrizes definidas no planejamento de gestão. Assim, conclui-se que as deliberações trataram dos meios. Cabe ressaltar que os objetivos finais da política estão definidos em lei, e o comitê não teria legitimidade para alterá-los.

A dinâmica de funcionamento do comitê preenche os quesitos de Rafaghelli (2001). Entre reuniões ordinárias e extraordinárias, foi realizada em média uma por mês na gestão 2001/02, todas com atas posteriormente submetidas à aprovação em plenário. As atas continham as principais afirmações sobre os membros nos diversos assuntos, bem como os encaminhamentos definidos. Além de atas, a informação circulou por meio de informes. 
Com relação aos fatores condicionantes de Goma (2002), verificou-se que o comitê não os cumpre na sua totalidade. Durante a gestão estudada, ao contrário do que sugere o autor, as ações do comitê estiveram focadas na elaboração de um diagnóstico e de estratégias para envolvê-lo em um documento. O diagnóstico foi realizado com estudos técnicos contratados, as estratégias foram as definições de consultas à sociedade, e o documento será a proposta de enquadramento a ser encaminhada à Fundação Estadual de Proteção Ambiental Henrique Luís Roessler (Fepam). Entretanto, tais estratégias se dão pela articulação de redes participativas, pois ficou clara a importância do envolvimento das entidades-membro como disseminadoras do trabalho do comitê para a sociedade, no sentido de estimular a participação desta na elaboração da proposta de enquadramento. Está nas atribuições do comitê o encaminhamento da proposta de enquadramento, ou seja, a lei aparece como dificultador do sucesso do processo participativo, conforme sugerido por Goma (2002).

Outra condição sugerida pelo BID (2003) é o comprometimento do órgão promotor com o processo. Antes de realizar essa análise é necessário identificar quem é o órgão promotor. O comitê foi criado a partir de um decreto do governo do estado do Rio Grande do Sul. Partindo do princípio de que o órgão promotor é o governo do estado surge outra questão a ser esclarecida: como ele se relaciona com o comitê? Verificou-se que essa relação se dá de duas formas: a representação e a fiscalização. A representação acontece no grupo das entidades da administração direta. São oito vagas com direito a voto nas tomadas de decisão no comitê, mas que não foram totalmente preenchidas. Além disso, as vagas preenchidas não participaram das deliberações na gestão 2001/02. A fiscalização acontece pelos órgãos DRH, Fepam, SMAM e Metroplan. Por serem fiscalizadores e do estado, esses órgãos fazem o papel da lei na gestão da bacia do Guaíba, pois de certa forma as decisões do comitê dependem de posterior aprovação dos mesmos. Ao contrário do que aconteceu quando atuou como representante, o governo participou como fiscalizador.

Ainda que a análise da participação do estado - representado pelas entidades da administração direta no comitê — não seja o foco deste artigo, chama a atenção a sua não-participação no período considerado. Acredita-se que isso se deva a uma maior valorização do seu papel como fiscalizador. $\mathrm{Ou}$ seja, na medida em que as deliberações do comitê não são implementadas sem a sanção de outros órgãos do estado, como o Departamento de Recursos Hídricos da Secretaria do Meio Ambiente, parece haver uma ênfase na decisão final, e um menosprezo do processo de gestão participativa. 


\section{Considerações finais}

Como visto anteriormente, os sistemas de gestão dos recursos hídricos têm avançado em nível de complexidade. O modelo preconizado na legislação brasileira, sistêmico de integração participativa, é bastante complexo por envolver todos os interessados no recurso e utilizar instrumentos inovadores. Um deles é a participação da sociedade. Com o objetivo de analisar esta inovação no Comitê Lago Guaíba, o presente trabalho revelou pontos positivos. Verificou-se a participação de grupos e organizações que representam a sociedade civil, bem como uma efetiva influência dos mesmos nas decisões do comitê. Da mesma forma aconteceu com os usuários da água.

A pesquisa revelou também que o comprometimento do governo do estado como órgão promotor não acontece no processo participativo do Comitê Lago Guaíba. Existe um comprometimento dele como promotor do Sistema de Recursos Hídricos no estado.

Apesar de se ter estudado apenas um caso, pode-se colocar em questão a composição dos comitês prevista nos arts. 13 e 14 da Lei no 10.350/94. Entretanto, a participação da sociedade civil e de órgãos estaduais responsáveis pela fiscalização das ações do comitê indica que, mesmo que a passos lentos, a gestão das águas no Rio Grande do Sul caminha na direção da democracia e da sustentabilidade.

\section{Referências bibliográficas}

ARNSTEIN, S. Partnerships online. Reino Unido, 1998. Disponível em <www. partnerships.org.uk/part/arn.htm>. Acesso em: 15 mar. 2003.

BID (BANCO INTERAMERICANO DE DESENVOLVIMENTO). Libro de consultas sobre participación. 199-. Disponível em: <www.iadb.org/exr/ESPANOL/politicas/participa/ indice.htm >. Acesso em: 15 maio 2003.

BRASIL. Constituição (1988). São Paulo: Saraiva, 2000.

CÁNEPA, E. M. A Lei das Águas no Rio Grande do Sul: no caminho do desenvolvimento sustentável? Ciência \& Ambiente, Santa Maria, v. 1, n. 21, p. 135-152, jul. 2000.

et al. Os comitês de bacia no RS: formação, dinâmica de funcionamento e perspectivas. Associação Brasileira de Engenharia Sanitária e Ambiental — Divisão RS. Porto Alegre, 2001. Disponível em: <www.abes-rs.org.br/rechid/comites-2>. Acesso em: 29 jan. 2003. 
CARVALHO, M. do C. A. A participação social no Brasil hoje. Polis Papers, São Paulo, n. 2, 1998. Disponível em: <www.polis.org.br/obras/arquivo_169.pdf>. Acesso em: 3 mar. 2008.

COMITÊ LAGO GUAÍBA. Regimento interno. Porto Alegre, 1999.

. Ata da 12ª reunião ordinária. Porto Alegre, 2001a.

. Ata da 13ª reunião ordinária. Porto Alegre, 2001b.

. Ata da reunião extraordinária. Porto Alegre, 2001c.

. Ata da reunião extraordinária - workshop. Porto Alegre, 2001d.

. Ata da 16a reunião ordinária. Porto Alegre, 2001e.

. Ata da reunião extraordinária. Porto Alegre, 2001f.

. Ata da 17ª reunião ordinária. Porto Alegre, $2001 \mathrm{~g}$.

. Ata da reunião extraordinária. Porto Alegre, 2001h.

. Ata da $18^{\underline{a}}$ reunião ordinária. Porto Alegre, 2002a.

. Ata da reunião extraordinária. Porto Alegre, 2002b.

. Ata da 19a reunião ordinária. Porto Alegre, 2002c.

. Ata da reunião extraordinária. Porto Alegre, 2002d.

. Ata da $20^{a}$ reunião ordinária. Porto Alegre, 2002e.

. Ata da reunião extraordinária. Porto Alegre, $2002 \mathrm{f}$.

. Ata da $22^{\underline{a}}$ reunião ordinária. Porto Alegre, 2002g.

. Ata da reunião extraordinária. Porto Alegre, 2002h.

. Ata da 23a reunião ordinária. Porto Alegre, 2002i.

. Ata da reunião extraordinária. Porto Alegre, 2002j.

. Relatório de atividades da gestão 2001/2002. Porto Alegre, 20021.

. Informe circular 12/02. Porto Alegre, 2002m.

. Plano de bacia do lago Guaíba; participe deste processo e decida o futuro das nossas águas. Porto Alegre, 2002n.

COSTA, F. L. Termos de referência para avaliação da participação induzida na gestão de políticas públicas. In: CONGRESO INTERNACIONAL DEL CLAD SOBRE LA REFORMA DEL ESTADO Y DE LA ADMINISTRACIÓN PÚBLICA, 6., 2001, Buenos Aires. Anais eletrônicos... Buenos Aires: Clad, 2001. Disponível em: <www.clad.org. ve/siare/index.htm > . Acesso em: 31 maio 2003. 
DEMO, P. Participação é conquista. São Paulo: Cortez, 1993. . Pobreza política. 5. ed. Campinas: Autores Associados, 1996.

ESTRELLA, M.; GAVENTA, J. Who counts reality? Participatory monitoring and evaluation: a literature review. IDS Working Paper 70. 1997. Disponível em: <www. worldbank.org/participation/pme/webfiles/IDSwp70_PME.pdf >. Acesso em: 31 out. 2002.

FERREIRA, A. B. de H. Novo dicionário Aurélio. Rio de Janeiro: Nova Fronteira, 1975.

FONT, J. Mecanismos de participación ciudadana en la toma de decisiones locales: una visión panorámica. In: CONGRESO INTERNACIONAL DEL CLAD SOBRE LA REFORMA DEL ESTADO Y DE LA ADMINISTRACIÓN PÚBLICA, 6., 2001, Buenos Aires. Anais eletrônicos... Buenos Aires: Clad, 2001. Disponível em: <www.clad.org. ve/siare/index.htm >. Acesso em: 31 maio 2003.

GOHN, M. da G. Conselhos gestores e participação sociopolítica. São Paulo: Cortez, 2001. v. 1. p. 120.

GOMA, R. Gobiernos locales y redes participativas: retos e innovaciones. In: CONGRESO INTERNACIONAL DEL CLAD SOBRE LA REFORMA DEL ESTADO Y DE LA ADMINISTRACIÓN PÚBLICA, 7., 2002, Lisboa. Anais eletrônicos... Lisboa: Clad, 2002. Disponível em: <www.clad.org.ve/siare/index.htm>. Acesso em: 31 maio 2003.

LANNA, A. E. Sistemas de gestão de recursos hídricos: análise de alguns arranjos institucionais. Ciência \& Ambiente, Santa Maria, v. 1, n. 21, p. 21-56, jul. 2000.

LIMA, R. B. O princípio da participação em gestão ambiental: a fronteira entre o gerir e o gestar.In:ENCONTRODASOCIEDADEBRASILEIRADEECONOMIAECOLÓGICA, 4., 2001, Belém. Anais... Belém, 2001. Disponível em: < nepam unicamp.br/ecoeco/artigos/encontros/ iv_en/mesa4/4.pdf>. Acesso em: 29 jun. 2003.

MODESTO, P. Participação popular na administração pública: mecanismos de operacionalização. JusVigilantibus. Vitória, 1999. Disponível em: <www.apoena.adv. br/participacao-popular-na-administ>. Acesso em: 15 mar. 2003.

NEBOT, C. P. Mejora de la gobernabilidad en el nivel de gobierno local: participación de más actores en el proceso presupuestario. In: CONGRESO INTERNACIONAL DEL CLAD SOBRE LA REFORMA DEL ESTADO Y DE LA ADMINISTRACIÓN PÚBLICA, 7., 2002, Lisboa. Anais eletrônicos... Lisboa: Clad, 2002. Disponível em: <www.clad. org.ve/siare/index.htm> Acesso em: 31 maio 2003.

PRÓ-GUAÍBA. Porto Alegre. Disponível em: <www.proguaiba.rs.gov.br>. Acesso em: 8 jul. 2003. 
RAFAGHELLI, J. Retos de desarrollar las condiciones para la participación ciudadana en escenarios locales. In: CONGRESO INTERNACIONAL DEL CLAD SOBRE LA REFORMA DEL ESTADO Y DE LA ADMINISTRACIÓN PÚBLICA, 6., 2001, Buenos Aires. Anais eletrônicos... Buenos Aires: Clad, 2001. Disponível em: <www.clad.org. ve/siare/index.htm>. Acesso em: 31 maio 2003.

RIO GRANDE DO SUL. Lei no 10.350, de 30 de dezembro de 1994. Institui o Sistema Estadual de Recursos Hídricos. Sistema Legis, Porto Alegre. Disponível em: $<$ www.al.rs.gov.br/legis/m010/m0100018.asp?hid_idnorma $=12501 \&$ texto $=>$. Acesso em: 2 jul. 2003.

Decreto no 38.989, de 29 de outubro de 1998. Cria o Comitê de Gerenciamento da Bacia Hidrográfica do Guaíba. Sistema Legis, Porto Alegre. Disponível em: <www.al.rs.gov.br/legis/m010/m0100018.asp?hid_idnorma $=5802 \&$ texto $=>$. Acesso em: 2 jul. 2003.

Fundação Estadual Proteção Ambiental. Qualidade ambiental. Porto Alegre, 200-. Disponível em: <www.fepam.rs.gov.br/qualidade/guaiba.asp> Acesso em: 24 jun. 2003.

TEIXEIRA, E. C. As dimensões da participação cidadã. Caderno CRH, Salvador: Universidade Federal da Bahia, v. 10, n. 26, 2007. Disponível em: <www.cadernocrh. ufba. br/include/getdoc.php?id $=1007 \&$ article $=198 \&$ modo $=p d f>$. Acesso em: 3 mar. 2008. 